\title{
The effect of consecutive ambient air pollution on the hospital admission from chronic obstructive pulmonary disease in the Chengdu region, China
}

\author{
Yi Zhang ${ }^{1,2}$ (1) $\cdot$ Ziyue Wang ${ }^{1,2} \cdot$ Yu Cao $^{1,2} \cdot$ Lifu Zhang $^{1,2} \cdot$ Guan Wang $^{1,2} \cdot$ Fangjie Dong $^{3} \cdot$ Ren Deng $^{4} \cdot$ Baogen Guo $^{5}$.

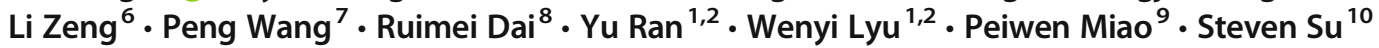

Received: 26 October 2020 / Accepted: 11 February 2021 / Published online: 18 March 2021

(C) The Author(s), under exclusive licence to Springer Nature B.V. 2021

\begin{abstract}
Hospitalisation risks for chronic obstructive pulmonary disease (COPD) have been attributed to ambient air pollution worldwide. However, a rise in COPD hospitalisations may indicate a considerable increase in fatality rate in public health. The current study focuses on the association between consecutive ambient air pollution (CAAP) and COPD hospitalisation to offer predictable early guidance towards estimates of COPD hospital admissions in the event of consecutive exposure to air pollution. Big data analytics were collected from 3-year time series recordings (from 2015 to 2017) of both air data and COPD hospitalisation data in the Chengdu region in China. Based on the combined effects of CAAP and unit increase in air pollutant concentrations, a quasiPoisson regression model was established, which revealed the association between CAAP and estimated COPD admissions. The results show the dynamics and outbreaks in the variations in COPD admissions in response to CAAP. Cross-validation and mean squared error (MSE) are applied to validate the goodness of fit. In both short-term and long-term air pollution exposures, $Z$ test outcomes show that the COPD hospitalisation risk is greater for men than for women; similarly, the occurrence of COPD hospital admissions in the group of elderly people ( $>65$ years old) is significantly larger than that in lower age groups. The time lag between the air quality and COPD hospitalisation is also investigated, and a peak of COPD hospitalisation risk is found to lag 2 days for air quality index (AQI) and $\mathrm{PM}_{10}$, and 1 day for $\mathrm{PM}_{2.5}$. The big data-based predictive paradigm would be a measure for the early detection of a public health event in post-COVID-19. The study findings can also provide guidance for COPD admissions in the event of consecutive exposure to air pollution in the Chengdu region.
\end{abstract}

Yi Zhang and Ziyue Wang contributed equally to this work.

\author{
Yi Zhang \\ yi.zhang@uestc.edu.cn \\ Fangjie Dong \\ dongfj@nhc.gov.cn \\ Ziyue Wang \\ ntu.wangzy@gmail.com \\ $\mathrm{Yu}$ Cao \\ caoy.csu@gmail.com \\ Lifu Zhang \\ lifu@std.uestc.edu.cn \\ Guan Wang \\ wangguan@std.uestc.edu.cn \\ Ren Deng \\ dengren@schnic.cn \\ Baogen Guo \\ guobaogen@163.com
}

\author{
Li Zeng \\ Lc_zenglie@163.com \\ Peng Wang \\ gd-bs@163.com \\ Ruimei Dai \\ luckyplum.dai@gmail.com \\ Yu Ran \\ yu.ran@std.uestc.edu.cn \\ Wenyi Lyu \\ lwy0352@163.com \\ Peiwen Miao \\ ssicau.mpw@gmail.com \\ Steven $\mathrm{Su}$ \\ steven.su@uts.edu.au
}

Extended author information available on the last page of the article 
Keywords Consecutive ambient air pollution $\cdot$ Chronic obstructive pulmonary disease $\cdot$ Big data analytics $\cdot$ Hospital admission . Air pollutant concentration

\section{Introduction}

Chronic Obstructive Pulmonary Disease (COPD) is one of the most common chronic respiratory diseases (CRDs) that generally cause limitations in lung airflow (Sadatsafavi and Sin 2015). The progression of COPD is the major burden of morbidity, disability, and premature mortality for public health worldwide (Thom 1989; Mannino and Buist 2007; Yin et al. 2016). The WHO has shown that approximately $91 \%$ of the total world's population lives in places where the air pollutant level exceeds the threshold of ambient air pollution limits and suffers from a threat to respiratory health (Chen et al. 2013). Microscopic pollutants mostly formed by fossil fuel combustion are key factors associated with respiratory diseases, particularly with COPD. Specifically, $\mathrm{PM}_{2.5}$ with an aerodynamic diameter between 2.5 and 2.8 microns is confirmed as a cause of COPD (González et al. 2019). The WHO estimates that in 2016, exposure to $\mathrm{PM}_{2.5}$ causes 4.2 million premature deaths worldwide $(91 \%$ of which occur in low- and middle-income countries), while $18 \%$ of mortality is due to COPD and acute lower respiratory infections (Sadatsafavi and Sin 2015; Chen et al. 2013; Sin et al. 2006). Current studies on air pollutionrelated COPD are often analysed based on the recorded data of hospital admissions, which can effectively present the temporal information from exposure to air pollution to a clinical presentation of COPD (Qiu et al. 2019; Zhu et al. 2019; Qiu et al. 2018; Lin et al. 2018; Qiu et al. 2013; Bai et al. 2019). However, little studies related to the consecutive effect of ambient air pollution on COPD hospitalisations have been addressed. More importantly, WHO has identified that respiratory health is correlated with short- or long-term exposure to air pollutants (Peng et al. 2020; Sun et al. 2018).

According to WHO reports in 2016, the annual mean particulate matter concentration of the largest cities has exceeded $10 \mu \mathrm{g} / \mathrm{m}^{3}$ (WHO air quality guideline) and had a more than 5\% annual increase during 1998-2012 (Chen et al. 2013; Organization WH 2016). For instance, Chengdu had heavy $\mathrm{PM}_{2.5}$ pollution $\left(>35 \mu \mathrm{g} / \mathrm{m}^{3}\right.$ ) from 1998 to 2012 (Han et al. 2015). In the post-COVID-19 era, public health is the priority of both the public and governments around the world, and therefore, the predictive early guidance for the underlying hospitalisation burden is required in current hospital systems to reasonably allocate medical resources before any public events occur (Fang et al. 2011; Halpern et al. 2003).

Most current studies only investigated non-consecutive factors (e.g., ambient air pollutant concentrations (Jo et al. 2018; Halonen et al. 2008; Peacock et al. 2011), sociodemographic characteristics (Schikowski et al. 2014a; Çiftçi et al. 2014; Lindberg et al. 2006), and climate environment (Qiu et al.
2013; Krahnke et al. 2013; Hoffmann et al. 2018)). On the other hand, studies that examined the effects of long-term exposure to air pollution have been focusing on the mean concentration of air pollutants over the course of several years. Their findings cannot provide effective guidance to predict the association between periodic Consecutive Ambient Air Pollution (CAAP) and COPD hospitalisations. The effects of continuous exposure to air pollution in relation to the increase in COPD-related hospital admissions have not been well investigated. Moreover, since cross-regional differences exist in COPDrelated hospital admissions, big data analytics derived from a single regional population are necessary to estimate COPD hospitalisations under specific CAAP conditions. In the present study, a Chengdu-based time series analysis is employed to examine COPD hospital admissions in relation to daily CAAP. As reported by (Ning et al. 2019; Qiao et al. 2015; Zhang et al. 2020), because of its low-lying basin topography, Chengdu is especially susceptible to the risk of the consecutiveness of ambient air pollution. Based on our preliminary studies (Zhang et al. 2020), CAAP was confirmed as an independent key variable for the hospital admission of COPD in the Chengdu region China. Following this idea, the effect of CAAP on the hospital admission from COPD will be modelled and estimated in this study.

\section{Methods}

\section{Study sites}

In urban districts of Chengdu city, air pollutant monitoring stations were located at 8 meteorological observatories for the real-time availability of ambient air pollutant measurements. Medical Record Homepage (MRH) data across 936 public hospitals in Chengdu were used in the analysis. Notably, the study sites were located not only in the main urban area of Chengdu but also in the surrounding jurisdictions. With a special concern of MRH data ethics, all personal privacy information (e.g., name, ID, and hospital name) has been removed from the study. COPD admission data were excluded from the current study if either International Classification of Diseases (ICD) codes or the diagnosis date in the diagnosis report is not properly entered. Such air pollutant concentration data was excluded if it is less than $25 \%$ of interquartile range (IQR) or more than $75 \%$ of IQR. Figure 1 shows the locations and numbers of air pollutant monitoring stations and hospitals in the Chengdu region. 


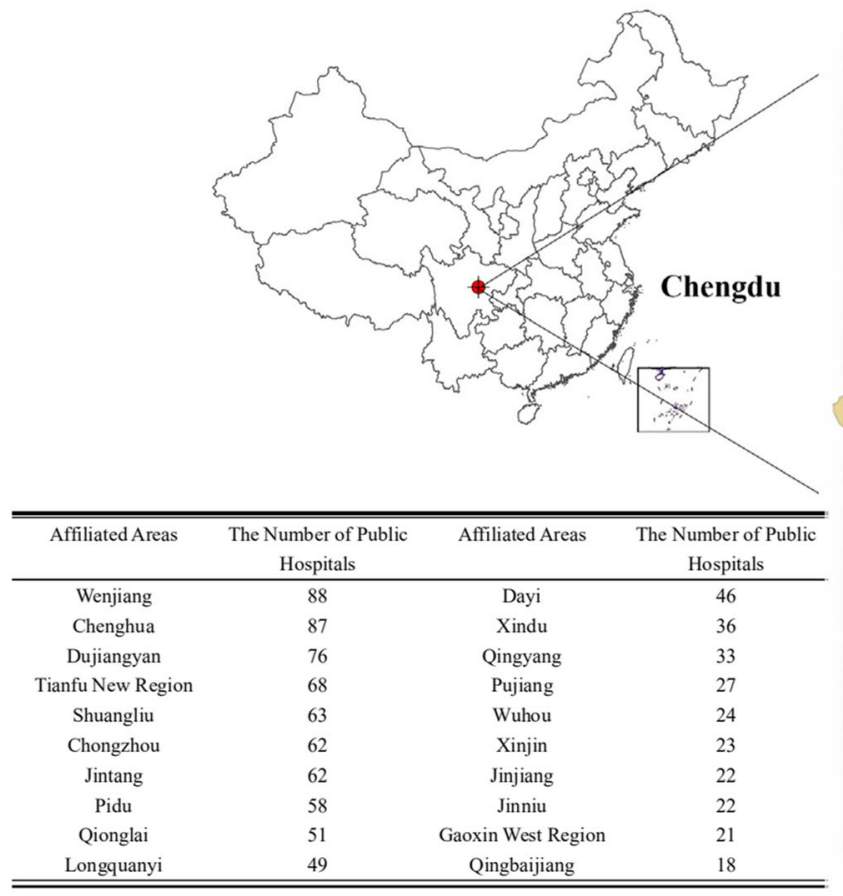

Fig. 1 The locations and numbers of air pollutant monitoring stations and public hospitals in Chengdu. The red star indicates 8 real-time monitoring stations in meteorological observatories, i.e., Sanwa Kiln, Shilidian, Junping Street, Liangjiaxiang, Shahepu, Lingyan Temple, Caotang

\section{Data collection}

The primary diagnosis of COPD was individually recorded on the MRH online system. All hospitals are obligated to upload MRH data periodically to the Health and Family Planning Commission of Chengdu. The University of Electronic Science and Technology of China (UESTC) and its owned enterprise, Chengdu UESTC Goldisc Multimedia Technology Co., Ltd., were approved for the use of data. From the 3-year database records (2015-2017), a total of 111,740 COPD admissions were authorized for the use of this study. The hospital admissions for COPD diseases included COPD with acute lower respiratory tract infection (J44.0), COPD with acute exacerbation (J44.1), other specified COPD (J44.8), chronic bronchitis with emphysema (J44.801, J44.803), chronic asthmatic bronchitis (J44.802, J44.804), chronic bronchiolitis (J44.805), chronic obstructive bronchitis (J44.806), and unspecified COPD (J44.9). For each admission, the date of admission, the primary diagnosis (ICD10 codes and texts), gender, and age were extracted for the study.

The air quality data in which the AQI index exceeds 100, referred to as AQI level 3 in Ambient Air Quality Standard of China 2012 (AAQSC-2012), are labelled as the air-polluted data and extracted for the big data-related analyses. CAAP is defined as such circumstance where an AQI index is

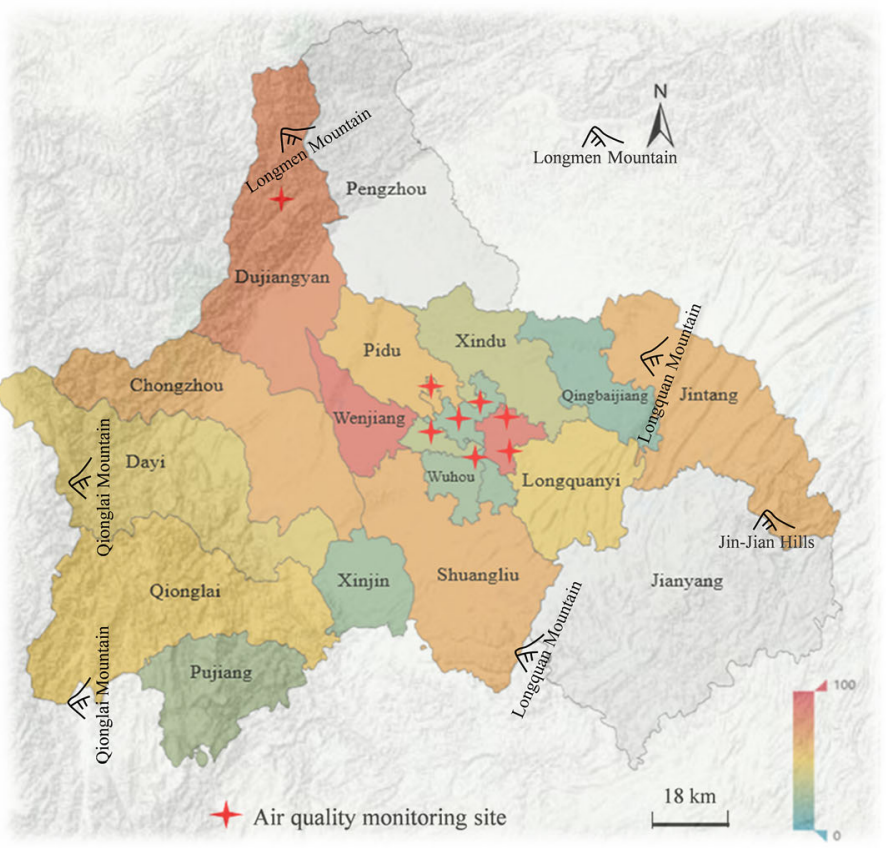

Temple, and Jinquan Lianghe. The colour bar represents the number of public hospitals in CBD, suburbs, and townships in Chengdu (Zhang et al. 2020).

consecutively more than 100 in the number of days (Table 1). Then, the CAAP data of different durations were integrally saved as time series data. These data included the pollutant concentrations for $\mathrm{PM}_{2.5}, \mathrm{PM}_{10}, \mathrm{SO}_{2}, \mathrm{NO}_{2}, \mathrm{CO}, \mathrm{O}_{3}$, and AQI. The ambient air quality data in the region of Chengdu were acquired from a publicly accessible web source, namely, the China National Environmental Monitoring Center (http://www.cnemc.cn/).

The consecutive polluted dates and data across all 3-year air quality data were manually extracted. The COPD admission data were divided into two conditions, air-polluted and non-air-polluted admissions. In each calendar year, the annual mean of COPD admissions of non-air-polluted days was set as a reference level in case of any cross-year errors. Then, based on the annual time series, the lag of the appearance of COPD admission in response to the corresponding air-polluted time series was estimated. For instance, a lag of 2 days means that the COPD data paired with the CAAP-based air data is selected by 2 days after the first consecutive air-polluted day.

To investigate the subgroup robustness, data from continuous exposure to pollution were divided into short-term (2-9 days) and long-term (more than 10 days) air pollution exposures. Both short-term and long-term effects were analysed based on age ( $0-65$ years, and $>65$ years) and gender (male and female). The $Z$ test was applied to provide statistical significance in subgroup analyses. 


\section{Statistical analysis}

The Poisson distribution test was used to estimate a series of COPD time series and found an over-dispersed Poisson distribution across the extracted CAAP-based COPD samples. First, a basic model was built by fitting quasi-Poisson regression in the generalized additive model (GAM) with basic attributable factors, that is, calendar time (CT), day-of-week (DoW), and public holiday (PH). The optimization procedure in GAM was taken based on the back-fitting algorithm (Dominici et al. 2002; Stieb et al. 2003). The base model can be expressed as:

$\log \left[E\left(Y_{t}\right)\right]=\alpha+\mathrm{ns}\left(\mathrm{CT}, d f=\frac{7}{\text { year }}\right)+\mathrm{DoW}+\mathrm{PH}$

where $E\left(Y_{t}\right)$ represents daily COPD hospital admissions on day $t, \alpha$ is the intercept, ns $(\cdot)$ is the natural cubic spline function, and $d f$ is the degree of freedom. Since the quantity of AQI values was assumed as a threshold to discriminate if the daily ambient air condition was polluted (Table 1), we applied the Spearman correlation test to assess the correlation between AQI and other air pollutant concentrations $\left(\mathrm{PM}_{2.5}, \mathrm{PM}_{10}, \mathrm{SO}_{2}, \mathrm{NO}_{2}, \mathrm{CO}\right.$, and $\left.\mathrm{O}_{3}\right)$. The air pollutants that are significantly correlated with the AQI will be considered as the individual attributable factors. The effects caused by the individual attributable factors can be depicted as:

$$
\log \left[E\left(Y_{t}\right)\right]=\alpha+\beta\left(C_{t-i}\right)+\mathrm{ns}\left(\mathrm{CT}, d f=\frac{7}{\text { year }}\right)+\mathrm{DoW}+\mathrm{PH}
$$

where $\beta(\cdot)$ is the log relative risk of COPD hospital admissions associated with a unit increase in the concentration of ambient air pollutant $\left(C_{t-i}\right)$, and $i$ is the lag in days. With an $i$ lag day pattern, the COPD data of the candidate day paired with one day's air pollutant concentration data lagged $i$ days behind the day of the air pollutant concentration data. Based on Eq. (2), the joint effect between consecutive air-polluted days $\left(D_{t-i}\right)$ and a unit increase of $C_{t-i}$ was added, which can be described as:

$$
\log \left[E\left(Y_{t}\right)\right]=\alpha+\gamma\left(C_{t-i}, D_{t-i}\right)+\mathrm{ns}\left(C T, d f=\frac{7}{\text { year }}\right)+\mathrm{DoW}+\mathrm{PH}
$$

where $\gamma(\cdot)$ is the log relative risk of COPD hospital admissions when a unit increase of $C_{t-i}$ and $D_{t-i}$ are interactively affected. By solving Eq. (3), the COPD morbidity burden can be estimated by:

$$
\mathrm{HA}_{t}=N \cdot\left[\exp \left(\xi \cdot \Delta C_{t-i}\right)-1\right]
$$

where $\mathrm{HA}_{t}$ is the number of COPD hospital admissions attributed to both $C_{t-i}$ and $D_{t-i}, N$ is the reported number of COPD admissions in 2015-2017 Chengdu, $\xi$ is the model coefficient on joint effect estimated from Eq. (3), and $\Delta C_{t-i}$ is the concentration difference between the actual concentration and annual mean concentration on day $t-i$. Based on Eq. (4), additional analyses for sex, age, and day lag pattern were also conducted.

Regarding the extracted consecutive air-polluted data, $\mathrm{PM}_{2.5}$ and $\mathrm{PM}_{10}$ were correlated to the AQI (Spearman correlation coefficient above 0.7 , shown in Table 4). However, other air pollutants $\left(\mathrm{SO}_{2}, \mathrm{NO}_{2}, \mathrm{CO}\right.$, and $\left.\mathrm{O}_{3}\right)$ were not attributable to the AQI and did not attain the pollution level defined in AAQSC-2012. Thus, the single-pollutant model was fitted merely with adjustment for AQI, $\mathrm{PM}_{2.5}$, and $\mathrm{PM}_{10}$.

The quasi-Poisson regression was used to obtain Chengdu-specific estimates. All statistical analyses were conducted in R software (version 3.2.2, R Development Core Team, Vienna, Austria). The outlier was replaced by the closest value among the maximum, minimum, median, and 75 th and 25 th percentiles. The results were reported as percentage changes with $95 \%$ confidence intervals in daily hospital admissions to an incremental increase in AQI, $\mathrm{PM}_{2.5}$, and $\mathrm{PM}_{10}$ concentrations.

In this study, the 3-year data on air pollutant concentrations and COPD hospitalisations from 2015 to 2017 were used. Both air quality data and COPD hospitalisation data under CAAP were identified and labelled (Siddiqi and Chong-Xian 1984). All indices of ambient air pollutant concentrations (i.e., $\mathrm{PM}_{2.5}, \mathrm{PM}_{10}$, sulfur dioxide $\left(\mathrm{SO}_{2}\right)$, nitrogen dioxide $\left(\mathrm{NO}_{2}\right)$, carbon monoxide $(\mathrm{CO})$, ozone $\left(\mathrm{O}_{3}\right)$, and $\left.\mathrm{AQI}\right)$ were statistically analysed. Spearman correlations in various consecutive air pollution durations were also provided. A quasiPoisson regression model was used to estimate COPD admissions in terms of consecutive air-polluted days, air pollutant concentrations, calendar time, and day of week. The age, gender, and lag effects on COPD hospitalisations under CAAP were estimated for the specific Chengdu region.

\section{Results}

Table 1 shows the Chinese technical regulation on ambient air quality complied by AAQSC-2012, which has been adopted in the selection criteria of CAAP in this study design. Table 2 shows the quantities and percentages of the gender, age, number of days when air pollutant levels exceeded the polluted levels for each air pollutant, and category of COPD. A total of 65,104 patients were male, and $41.74 \%$ were female. Elderly individuals comprised the main group, and 
Table 1 Technical regulation on ambient air quality (\#HJ633-2012) followed by AAQSC-2012 and implemented from January 1, 2016

\begin{tabular}{|c|c|c|c|c|}
\hline AQI & $\begin{array}{l}\text { AQI } \\
\text { level }\end{array}$ & $\begin{array}{l}\text { Pollution } \\
\text { level }\end{array}$ & Health impact & Suggestions and measures \\
\hline $0 \sim 50$ & 1 & Good & None of health implications & Normal outdoor activities \\
\hline $51 \sim 100$ & 2 & Moderate & $\begin{array}{l}\text { Air quality is acceptable, but may have weak } \\
\text { health impacts for allergic people }\end{array}$ & $\begin{array}{l}\text { Outdoor activities should be limited for the small groups of allergic } \\
\text { people }\end{array}$ \\
\hline $101 \sim 150$ & 3 & $\begin{array}{l}\text { Lightly } \\
\text { polluted }\end{array}$ & $\begin{array}{l}\text { Mild exacerbation and irritating symptoms are } \\
\text { occurred in susceptible and healthy people, } \\
\text { respectively }\end{array}$ & $\begin{array}{l}\text { Children, elders, and patients who suffer from heart or respiratory } \\
\text { problems should reduce long-time, high-intensity outdoor } \\
\text { activities }\end{array}$ \\
\hline $151 \sim 200$ & 4 & $\begin{array}{l}\text { Moderately } \\
\text { polluted }\end{array}$ & $\begin{array}{l}\text { Further exacerbated in susceptible groups, and } \\
\text { may influence the cardiorespiratory system of } \\
\text { healthy people }\end{array}$ & $\begin{array}{l}\text { Children, elders, and patients who suffer from heart or respiratory } \\
\text { problems should avoid long-time, high-intensity outdoor } \\
\text { activities; moderate reductions of outdoor activities for normal } \\
\text { people }\end{array}$ \\
\hline $200 \sim 300$ & 5 & $\begin{array}{l}\text { Heavily } \\
\text { polluted }\end{array}$ & $\begin{array}{l}\text { Symptoms for cardiorespiratory patients are } \\
\text { significantly exacerbated, and commonly } \\
\text { appeared in healthy people }\end{array}$ & $\begin{array}{l}\text { Children, elders, and patients who suffer from heart or respiratory } \\
\text { problems should stay at an indoor environment, and stop } \\
\text { outdoor activities; normal people reduce outdoor activities }\end{array}$ \\
\hline$>300$ & 6 & $\begin{array}{l}\text { Severely } \\
\text { polluted }\end{array}$ & $\begin{array}{l}\text { Healthy people have strong symptoms and } \\
\text { decrease exercise tolerance; earlier appearance } \\
\text { for underlying diseases }\end{array}$ & $\begin{array}{l}\text { Children, elders, and patients who suffer from heart or respiratory } \\
\text { problems should stay at an indoor environment and avoid } \\
\text { physical activities; normal people avoid outdoor activities }\end{array}$ \\
\hline
\end{tabular}

$81.65 \%$ of patients were aged above 65 years old. In total, 303 days were classified as air-polluted in the 3-year database, in which $\mathrm{PM}_{2.5}$ exceeded the polluted level for 245 days and $\mathrm{PM}_{10}$ exceeded the corresponding index for 175 days. In terms of the categories of COPD, COPD with acute exacerbation (J44.1) constituted $64.98 \%$ of all COPD hospitalisations, followed by chronic obstructive emphysema bronchitis with acute exacerbation (J44.101), which constituted $16.04 \%$.

Table 3 shows the results of descriptive statistics for the concentration of ambient air pollutants and COPD hospitalisations. Notably, both the median concentration and the mean concentration of $\mathrm{AQI}, \mathrm{PM}_{2.5}$, and $\mathrm{PM}_{10}$ exceeded the criteria defined in AAQSC-2012 (100, 75 $\mu \mathrm{g} / \mathrm{m}^{3}, 150 \mu \mathrm{g} / \mathrm{m}^{3}$, respectively); thus, $\mathrm{PM}_{2.5}$ and $\mathrm{PM}_{10}$ were considered the main contributors to ambient air pollution. COPD with acute exacerbation (J44.1) was by an interquartile range of 162 more prevalent than the other specific COPDs, indicating an acute reaction to exposure to ambient air pollution (Marsh et al. 2008).

Table 4 shows the results of the correlation analysis for concentrations of ambient air pollutants with each other

Table 2 Statistical results of gender, age, air pollutant concentrations, and cause-specific COPDs with ambient air pollution conditions based on the total 3-year (2015-2017) air data and hospital admission data recordings in Chengdu

\begin{tabular}{|c|c|c|c|c|c|c|}
\hline Category & & Quantities & $\begin{array}{l}\text { Percentage in the total } \\
\text { three-year dataset }(\%)\end{array}$ & Category** & Quantities & $\begin{array}{l}\text { Percentage in the } \\
\text { total three-year dataset }(\%)\end{array}$ \\
\hline \multirow[t]{2}{*}{ Gender } & Male & 65104 & 58.26 & $\mathrm{~J} 44.0$ & 4019 & 3.60 \\
\hline & Female & 46636 & 41.74 & $\mathrm{~J} 44.1$ & 72609 & 64.98 \\
\hline \multirow[t]{3}{*}{ Age (years old) } & $<44$ & 686 & 0.61 & $\mathrm{~J} 44.101$ & 17924 & 16.04 \\
\hline & $45-64$ & 19819 & 17.74 & $\mathrm{~J} 44.8$ & 182 & 0.16 \\
\hline & $\geq 65$ & 91235 & 81.65 & $\mathrm{~J} 44.801$ and $\mathrm{J} 44.803$ & 5204 & 4.66 \\
\hline \multirow{6}{*}{$\begin{array}{l}\text { Days of air pollutant concentrations } \\
\text { exceed the polluted level* }\end{array}$} & AQI & 303 & 27.67 & $\mathrm{~J} 44.802$ and $\mathrm{J} 44.804$ & 2431 & 2.18 \\
\hline & $\mathrm{NO}_{2}\left(\mathrm{ug} / \mathrm{m}^{3}\right)$ & 52 & 4.75 & $\mathrm{~J} 44.805$ & 179 & 0.16 \\
\hline & $\begin{array}{l}\mathrm{PM}_{2.5} \\
\quad\left(\mathrm{ug} / \mathrm{m}^{3}\right)\end{array}$ & 245 & 22.37 & J44.806 & 273 & 0.24 \\
\hline & $\mathrm{PM}_{10}\left(\mathrm{ug} / \mathrm{m}^{3}\right)$ & 175 & 15.98 & J44.9 & 8919 & 7.98 \\
\hline & $\mathrm{SO}_{2}\left(\mathrm{ug} / \mathrm{m}^{3}\right)$ & 0 & 0 & - & - & - \\
\hline & $\mathrm{CO}\left(\mathrm{ug} / \mathrm{m}^{3}\right)$ & 0 & 0 & - & - & - \\
\hline
\end{tabular}

*The statistical results were calculated by averaging the daily ambient air pollutant concentration data reached AQI level 3 referred to Table 1

**The cause-specific COPD codes refer to the ICD code released in 2013 


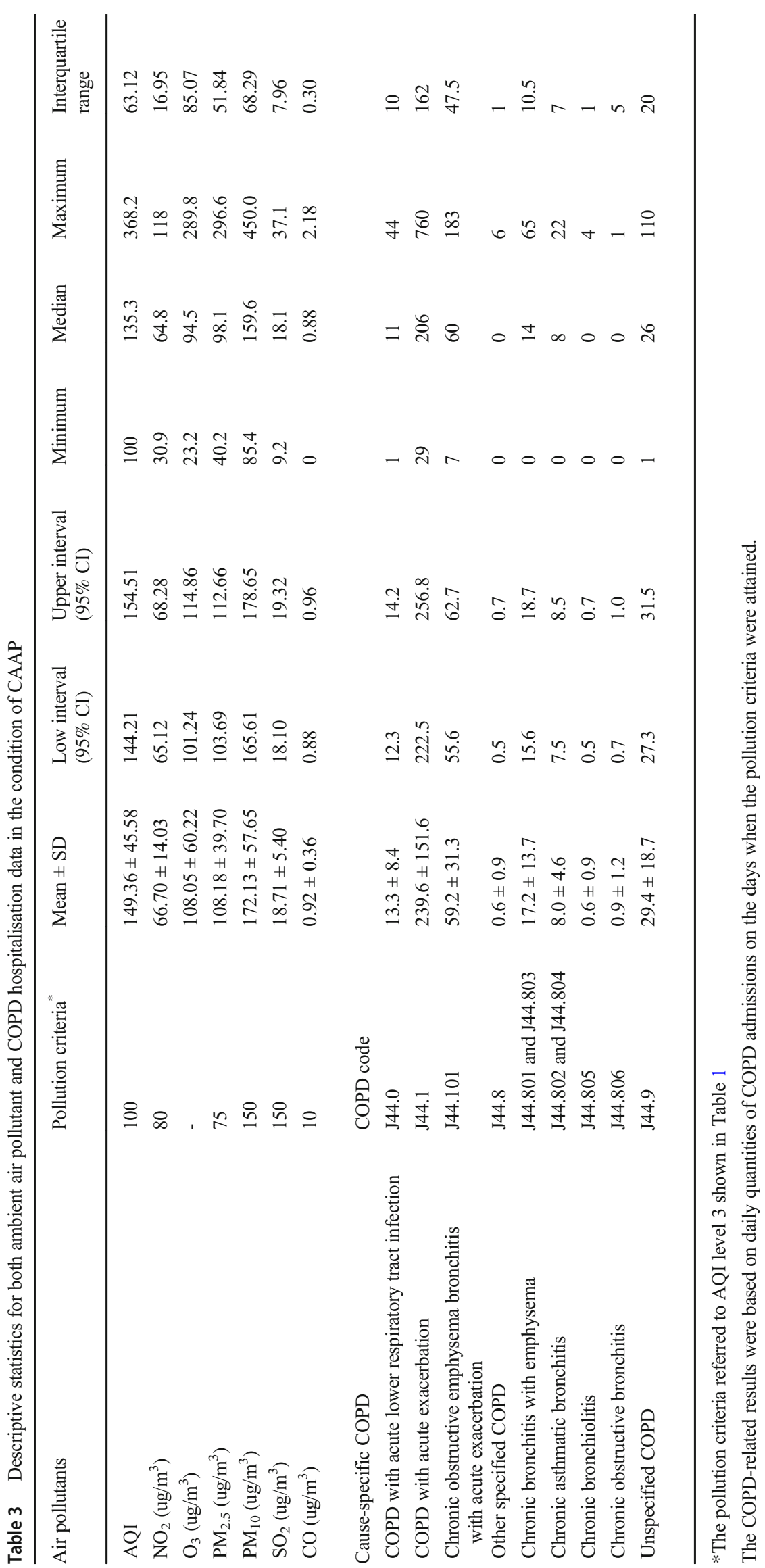


Table 4 Spearman correlation analysis across key ambient air pollutants in terms of short- and long-term effects of CAAP

\begin{tabular}{lcc}
\hline Variables & \multicolumn{2}{c}{ CAAP durative days } \\
\cline { 2 - 3 } & Short-term $(2 \sim 9$ days $)$ & Long-term (10 28 days) \\
\hline $\mathrm{PM}_{2.5}$ and AQI & $0.876^{* *}$ & $0.848^{* *}$ \\
$\mathrm{PM}_{10}$ and AQI & $0.869^{* *}$ & $0.835^{* *}$ \\
$\mathrm{NO}_{2}$ and AQI & $0.436^{* *}$ & $0.369^{* *}$ \\
$\mathrm{SO}_{2}$ and AQI & $0.266^{* *}$ & -0.116 \\
$\mathrm{CO}^{*}$ and AQI & $0.684 * *$ & $0.437^{* *}$ \\
$\mathrm{O}_{3}$ and AQI & $-0.316^{* *}$ & -0.208 \\
\hline
\end{tabular}

$* * p<0.01$

when the air was deemed polluted on 2 or more consecutive days. A significant positive correlation was confirmed in $\mathrm{PM}_{2.5}, \mathrm{PM}_{10}, \mathrm{NO}_{2}, \mathrm{SO}_{2}, \mathrm{CO}$ with AQI in the short-term pollution (less than 9 days), and $\mathrm{PM}_{2.5}, \mathrm{PM}_{10}, \mathrm{NO}_{2}, \mathrm{CO}$ with $\mathrm{AQI}$ in the long-term pollution (more than 9 days). Among these, it was notable that $\mathrm{PM}_{2.5}$ and $\mathrm{PM}_{10}$ were strongly positively correlated with the AQI variable in both short-term and long-term polluted effects.

Figure 2 shows the daily estimates of COPD hospital admissions in response to consecutive days of ambient air pollution with a 2-day lag using the joint model illustrated in Eq. 3. Compared with estimated admissions in the first outbreak (present on the second day), those in the second outbreak (presented on the 13th-19th, 9th-17th day, and 14th-28th days for $\mathrm{PM}_{2.5}, \mathrm{PM}_{10}$, and AQI, respectively) were much higher than the reference level (black horizontal line).

The ten cross-validations were performed to verify the goodness of fit and accuracy of the quasi-Poisson regression model (Eq. 3). In each repetition, a third of the data were randomly chosen to train the model, and the remaining data were used to test the model. The ten cross-validation results (Table 5) showed that the mean squared errors (MSEs) for $\mathrm{AQI}, \mathrm{PM}_{2.5}$, and $\mathrm{PM}_{10}$ in the mean of repetitions were 0.06 , 0.04 , and 0.03 , respectively. Figure 3 indicates the real COPD admission records (red) and the estimated COPD admissions (blue) derived from the quasi-Poisson regression model with CAAP illustrated in Eq. 3.

Figure 4 shows the estimated changes over $95 \%$ confidence intervals in percentage deviations (\%) of daily COPD admissions associated with 10-unit concentration increase of individual variables $\left(\mathrm{PM}_{2.5}, \mathrm{PM}_{10}\right.$, and $\left.\mathrm{AQI}\right)$ in short-term and long-term durations. The results by age group varied for different conditions. The short-term consecutive pollution significantly caused higher estimated changes than the long-term effect for both of two-age groups in the $\mathrm{PM}_{2.5}$ model ( $0-65$ years old: $3.84 \%$ (95\% CI: $2.65 \%, 5.03 \%)$ vs. $3.64 \%(95 \%$ CI: $2.15 \%, 5.13 \%)$, above 65 years old: $4.64 \%$ (95\% CI: $3.84 \%, 5.44 \%$ ) vs. $4.30 \%$ (95\% CI: $3.32 \%, 5.28 \%)$ ). However, the long-term effects in $\mathrm{PM}_{10}$ and AQI $(0-65$ years old: $2.57 \%$ (95\% CI: $1.31 \%, 3.83 \%)$ and $4.06 \%$ (95\% CI: $2.74 \%, 5.38 \%$ ), above 65 years old: $2.82 \%$ (95\% CI: $1.94 \%$, $3.70 \%)$ and $4.70 \%(95 \% \mathrm{CI}: 3.62 \%, 5.78 \%)$ ) were

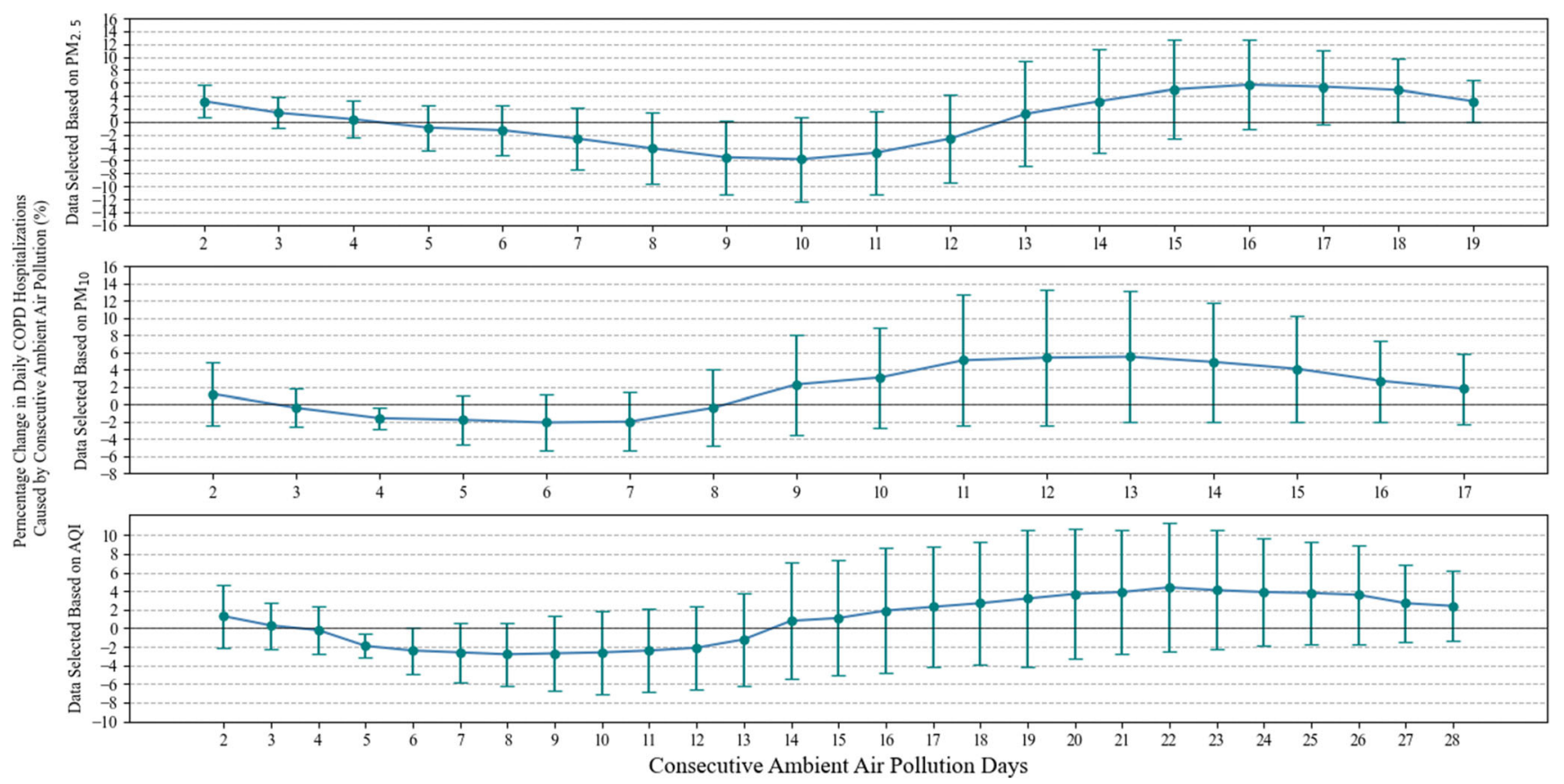

Fig. 2 Estimates of changes in COPD admissions in response to CAAP days. The percentage change $(\%)$ in daily hospitalisation was calculated by dividing the number of COPD admissions on certain CAAP day by the number of COPD admissions on the first CAAP day. For instance, the percentage change in the 10th CAAP day was a ratio of the number of admissions on the 10th CAAP day over that on the first CAAP day 
Table 5 MSE (mean squared error) for cross-validation of the regression model

\begin{tabular}{lllllllllllll}
\hline $\begin{array}{l}\text { Ambient air } \\
\text { pollutants }\end{array}$ & 1 & 2 & 3 & 4 & 5 & 6 & 7 & 8 & 9 & 10 & Mean of MSE \\
\hline $\mathrm{AQI}$ & 0.06 & 0.04 & 0.04 & 0.02 & 0.04 & 0.04 & 0.04 & 0.04 & 0.23 & 0.03 & 0.06 \\
$\mathrm{PM}_{2.5}$ & 0.04 & 0.01 & 0.06 & 0.04 & 0.03 & 0.02 & 0.04 & 0.01 & 0.03 & 0.16 & 0.04 \\
$\mathrm{PM}_{10}$ & 0.03 & 0.02 & 0.02 & 0.02 & 0.02 & 0.03 & 0.05 & 0.04 & 0.05 & 0.02 & 0.03 \\
\hline
\end{tabular}

significantly greater than the short-term effect ( $0-65$ years old: $2.53 \%$ (95\% CI: $1.34 \%, 3.72 \%$ ) and $3.92 \%$ (95\% CI: $2.60 \%$, $5.24 \%$ ), above 65 years old: $2.76 \%$ (95\% CI: $2.00 \%, 3.53 \%$ ) and $4.17 \%$ (95\% CI: $3.18 \%, 5.15 \%)$ ). Similar trends can be found in the estimates between male and female groups. In $\mathrm{PM}_{2.5}$ estimates, the short-term effects in both males and females were higher long-term effects. Due to the influence of $\mathrm{PM}_{10}$, the AQI in short-term pollution is lower than that in long-term pollution. In addition, the results of the $Z$ test showed that different age and gender groups have significant differences in most instances.

Figure 5 shows the average estimates of the association between individual variables and COPD admissions on different day lags. The observed results indicated a similar lag pattern in $\mathrm{PM}_{10}$ and $\mathrm{AQI}$, for which lag2 generates the highest estimates. For each 10-unit increase of $\mathrm{PM}_{10}$ and AQI, it can be observed that increments of admissions on the previous 2 days are $2.66 \%(95 \% \mathrm{CI}: 2.05 \%, 3.67 \%)$ and 3.56 (95\% CI:
$2.65 \%, 4.47 \%$ ), respectively. An earlier response for $\mathrm{PM}_{2.5}$ in lag1 showed the outcome with the highest estimate change of admissions, $4.74 \%$ (95\% CI: 3.76\%, 5.72\%).

\section{Discussion}

The association between the ambient air pollutant concentration and the number of COPD hospitalisations has been extensively researched in health informatics, environmental regulation, and big data analytics (Schikowski et al. 2014b; Chen et al. 2004; Garshick 2014). The results illustrated that ambient air pollution can significantly influence the morbidity of COPD, which is certainly indicated by COPD hospital admissions (Garshick 2014; Wang et al. 2015; Lee et al. 2007). However, few studies have investigated the estimates of COPD hospitalisations under CAAP. Furthermore, the phenomenon of CAAP in developing countries is still quite

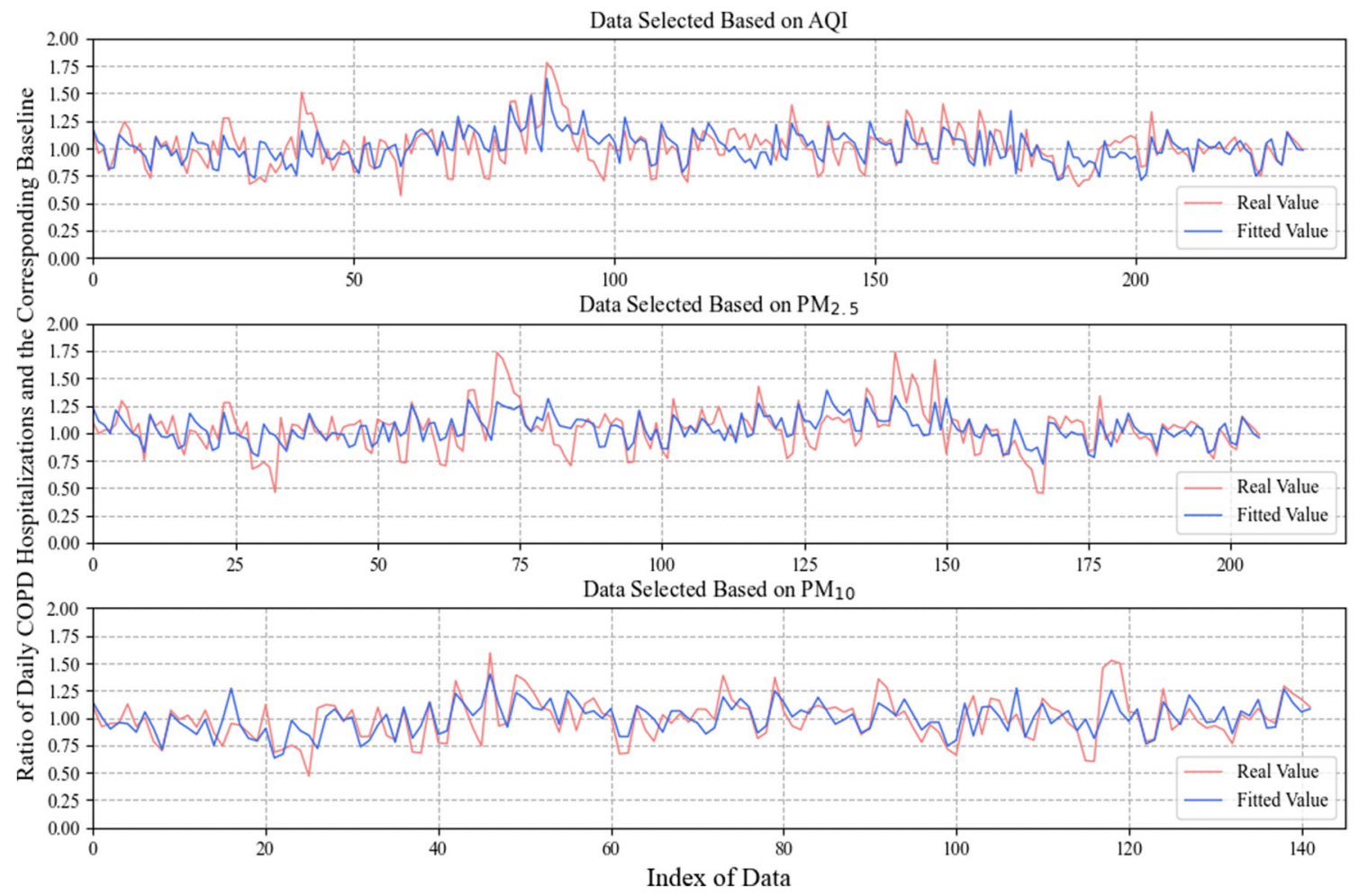

Fig. 3 The estimates of COPD admissions (in comparison to the real COPD records). The estimated outcomes were based on the quasi-Poisson regression model with CAAP, and the real outcomes were given from the Chengdu 3-year databases for both CAAP and COPD hospitalisations 

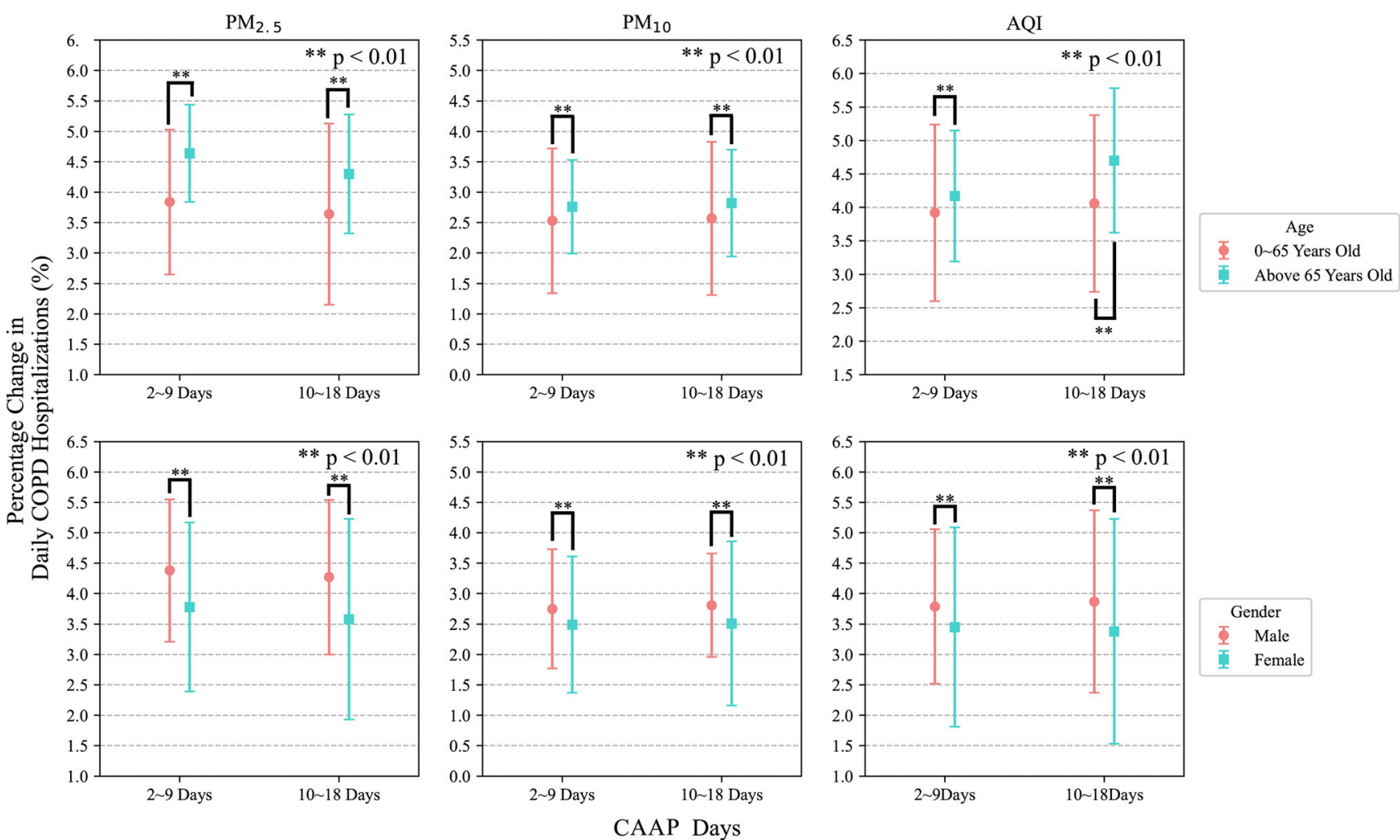

Fig. 4 Associations between $\mathrm{PM}_{2.5} / \mathrm{PM}_{10} / \mathrm{AQI}$ concentrations and COPD hospitalisations in short-term (2-9 CAAP days) and long-term (10-18 CAAP days) effects by age and gender using a single air pollutant model with a lag of 2 days (lag2)

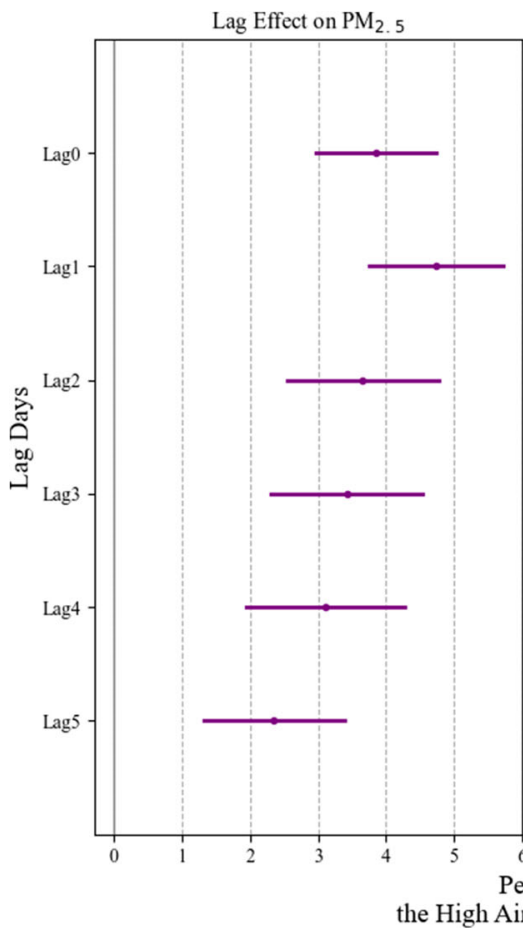

Fig. 5 Averaged percentage change (\%) in daily COPD admissions per 10-unit increase in $\mathrm{PM}_{2.5}, \mathrm{PM}_{10}$, and $\mathrm{AQI}$ concentrations on different lag days in Chengdu city, 2015-2017. For instance, lag1 represented that the
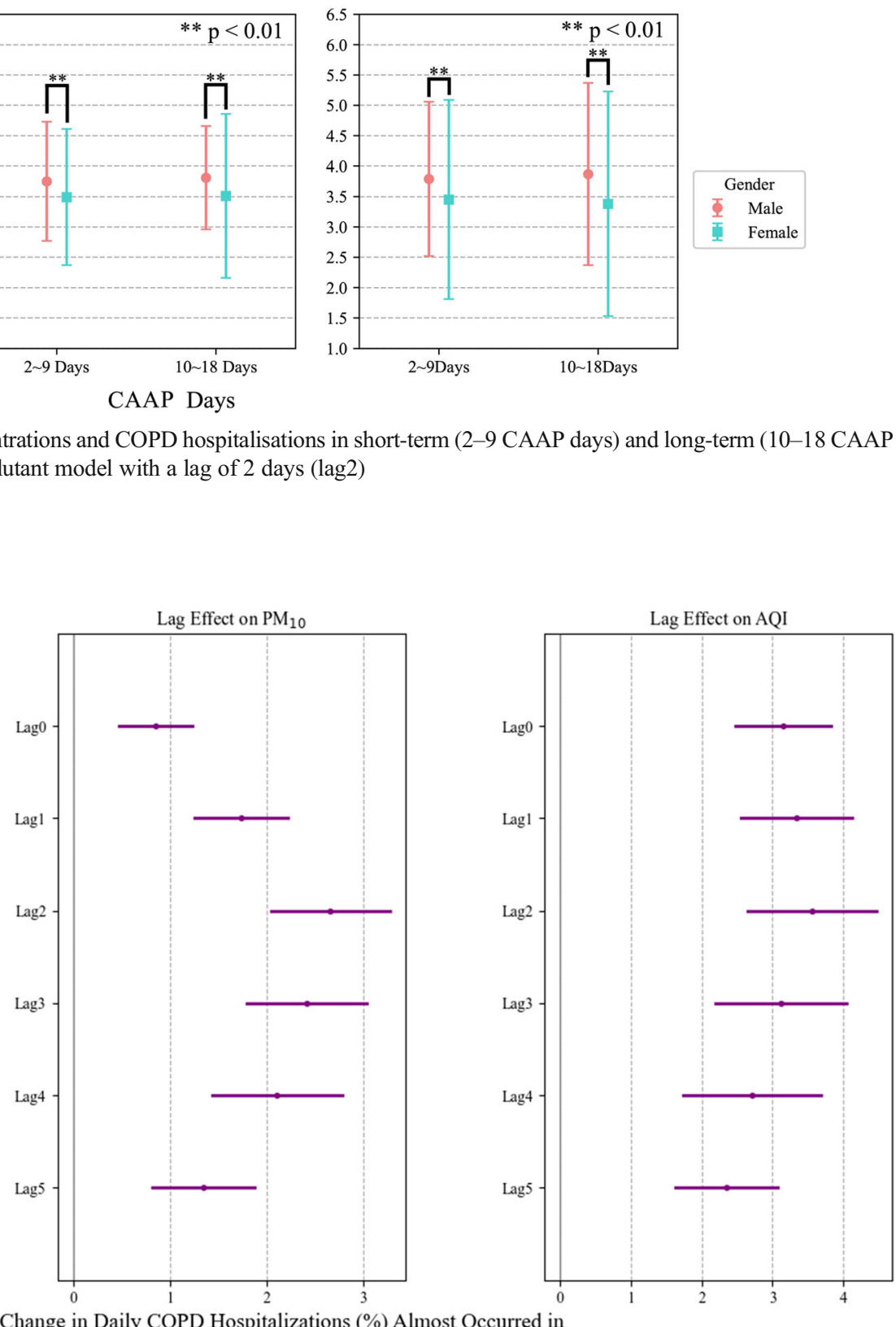
common, which may be a significant cause for medical burden in hospital systems (Mannino and Buist 2007; Fang et al. 2011; Li et al. 2016; Mehrotra et al. 2009; Sullivan et al. 2000). In the Chengdu region China, this phenomenon was also often publicly reported, compared with earlier studies for estimates of COPD hospitalizations with ambient air pollution (Zhu et al. 2019; Qiu et al. 2018), the major advantages of investigating CAAP-correlated COPD hospitalizations are to provide more reliable and accurate estimate for COPD admissions during the situation of CAAP. This study used the health big data tools to investigate the COPD hospitalisations and the corresponding consecutive airpolluted days in a specific region in China. Based on previous studies, a quasi-Poisson regression model was employed, which was structured by GAM and solved by the back-fitting algorithm (Lindberg et al. 2006; Dominici et al. 2002). General attributable factors (e.g., air pollutant concentrations, DOW, CT, and $\mathrm{PH}$ ) were adopted for the model establishment since they have been validated as the key factors associated with COPD hospitalisations (Qiu et al. 2018). Moreover, the consecutive air-polluted days $D_{t-i}$ (Eq. 3) were also defined as a joint effect with the concentration of ambient air pollutant $C_{t-i}$. With the joint model in Eqs. 3 and 4, the estimates of COPD hospitalisations under the condition of CAAP were built.

Figure 2 quantitatively depicts the dynamic trends of COPD admissions in response to consecutive ambient airpolluted days based on the quasi-Poisson regression model (Eq. 3). The findings showed that an initial outbreak of COPD admissions would emerge from the second CAAP day. After the initial surge, the hospital burden gradually decreased, as seen on the 3rd-10th days $\left(\mathrm{PM}_{2.5}\right)$, the 3rd7 th days $\left(\mathrm{PM}_{10}\right)$, and $3 \mathrm{rd}-9$ th days (AQI), meaning that the accumulative effects from the initial outbreak were gradually processing by hospitals. However, a subsequent outbreak of COPD admissions would eventually occur from the 11 th to 19 th days $\left(\mathrm{PM}_{2.5}\right)$, the 8 th to 17 th days $\left(\mathrm{PM}_{10}\right)$, and the 10th to 28th days (AQI), because CAAP was still lasting and its accumulative effects were causing the emergence of the second outbreak. The model output can reflect the tendency of COPD admissions in response to CAAP, and provide early guidance for the underlying outbreaks of COPD admissions.

Figure 5 shows the Chengdu average estimates of the associations between CAAP-based ambient air pollutants $\left(\mathrm{PM}_{2.5}, \mathrm{PM}_{10}\right.$, and $\left.\mathrm{AQI}\right)$ and COPD admissions on different lag days. Specifically, based on Eq. 4, lag day 2 generated the highest estimates for both $\mathrm{PM}_{10}$ and AQI. Therefore, the lag 2 was set to the quasi-Poisson regression model for predictive values demonstrated in Fig. 3.

The lag effect also was reported in national and sub-regions in China. National average percentage change in daily hospital admissions for cause-specific cardiovascular diseases per 10 $\mu \mathrm{g} / \mathrm{m}^{3}$ increase in $\mathrm{PM}_{2.5}$ concentrations in 184 Chinese cities during 2014-2017 was found that lag day 0 had the highest estimates for cardiovascular disease, ischaemic heart disease, heart failure, heart rhythm disturbances, and ischaemic stroke (Tian et al. 2019). Jinjun Ran et al. investigated effects of ambient benzene and toluene on COPD hospitalizations in Hong Kong from April 1, 2011 to December 31, 2014, and found that the cumulative 1-day lag effects of mean benzene and toluene have a significant percent excess risk (Ran et al. 2019). Hong Qiu et al. found that lag 3 day was greatest for exposure to $\mathrm{PM}_{10}, \mathrm{NO}_{2}$, and $\mathrm{SO}_{2}$ corresponding to the increase of COPD admissions, lag 2 day for $\mathrm{O}_{3}$ (Qiu et al. 2013). Li Peng et al. assessed the associations between particle number concentrations (PNCs) and COPD in Shanghai China from 2019 to 2011, and illustrated lag 0 was most prominent between PNCs and COPD, lag 1 particularly for particle size of $0.28-0.5 \mu \mathrm{m}$ and lag 2 for $0.25-0.28 \mu \mathrm{m}$ (Peng et al. 2020). Multi-city studies in Beijing, Shanghai, Guangzhou, and Hong Kong found that estimates of $\mathrm{PM}_{10}$ and $\mathrm{NO}_{2}$ for COPD had statistical significance and decreased from lag 0 to lag 4 (Meng et al. 2013).

Based on the above discussions, the CAAP was another essential individual risk factor linked to COPD hospitalisations, particularly in specific regions. In addition, the age and gender subgroups were also investigated in the context of CAAP. The finding in age subgroups was consistent with the conclusions made by most previous studies (Lindberg et al. 2006; Tian et al. 2019; Chang et al. 2005; Zeger et al. 2000) and has been confirmed to be mainly due to the weakness of immune and respiratory systems caused by ageing and comorbidities. Previous studies (Qiu et al. 2018) concluding that men are slightly more likely to be hospitalised from COPD, although there is no statistical significance, differed from the results of our studies. This may be due to the larger proportion of smokers among men than among women. Smoking did not lead to a rise of hospital admission in a short-term exposure of air pollution but would cause an aggravated effect in a long-term exposure of air pollution. The different correlated influences in gas and particles for COPD admissions in Chengdu have been previously reported in (Qiu et al. 2018). Due to the inadequate sample size limited by the CAAP selection criteria, the air pollutants (i.e., $\mathrm{NO}_{2}$ and $\mathrm{O}_{3}$ ) cannot be estimated by the quasi-Poisson regression model. The implications of temperature and relative humidity on COPD exacerbation have also been addressed in (Qiu et al. 2018).

The regression model had the following advantages for estimating COPD hospitalisations under CAAP: (1) the criteria for ambient air pollution followed AAQSC-2012 (Table 1), which was more suitable for the relative analyses of the Chengdu region; (2) the COPD admission provided 
from the electronic medical record of inpatients was more sensitive than the COPD morbidity (adopted in most previous studies (Peng et al. 2020; Kaji et al. 2014; Asche et al. 2008)) for the investigation of interactions between air pollution and COPD; (3) only the most correlated air pollutants (i.e., $\mathrm{PM}_{2.5}$ and $\mathrm{PM}_{10}$ ) can be selected for the model, which are significantly related and contributed to the AQI; (4) the reference COPD admission was set annually in order to avoid variability across multiple years; (5) although the study focused on the CAAP condition in a specific Chengdu region (especially from November to March of the following year), the methods proposed in this study were also applicable for other regions.

The limitations of this study are as follows: first, the mean daily concentration (approx. $24 \mathrm{~h}$ ), compared to the peak concentration hour of a day, was selected to represent the air pollutant concentration for a certain day. However, due to its property of dynamic variations across $24 \mathrm{~h}$, it might still obscure the true value of a day somehow. Second, individual factors such as smoking, occupation, and previous medical history related to the respiratory system were not considered in the study. Third, the diagnosed outcomes with false positives or false negatives may be inevitable, especially in smallscale hospitals in China (Hong-Wei and Infection DO 2019; Weiß et al. 2010; Guoliang 2012). Last but not least, the study samples also included districts where there were no monitoring stations. The reason why those districts outside the city centre were selected are because (1) Chengdu city centre and its administrative affiliated districts together (uncovering areas) are a whole plain located in a low-lying basin topography. And thus, the air pollution phenomenon is often simultaneous in this area; (2) the top (city- and province-level) public hospitals almost are located in Chengdu city centre, and people who resided in this area always would like to visit those hospitals for the diagnosis analysis of COPD; (3) it was supposed for local government to establish non-redundant monitoring stations in representations of the dynamical ambient air quality, as well as serve a predictive early guidance to not only the city area, but also its administrative affiliated districts.

\section{Conclusion}

This study investigated the association between CAAP and COPD hospitalisation based on 3-year data in Chengdu, China, from January 2015 to December 2017. The data were extracted based on AAQSC-2012. The statistical results showed that $\mathrm{PM}_{2.5}$ and $\mathrm{PM}_{10}$ were the most correlated air pollutants with the AQI index in both short-term and long-term exposures. The outcomes estimated by the established quasiPoisson regression model showed that the initial outbreak of COPD admissions occurred on the second consecutive air- polluted day, and a subsequent larger outbreak was followed by a decreased hospital burden. The model outputs were also compared with the real statistical results and validated via ten cross-validations. Age over 65 years old caused a higher risk for COPD admissions, while men had greater COPD admissions than women. The lag pattern showed a relatively stable day lag in the appearance of COPD admissions. The big data analytics in the study can be useful for the development of predictable early guidance for COPD hospitalisations under the CAAP condition.

Funding This work was supported by National Natural Science Foundation of China (\#61801094), Sichuan Science and Technology Program (\#2020YFH0093, \#21ZDYF3062), Major Science and Technology Special Projects in Sichuan (\#2020YFG0469), Fundamental Research Funds for the Central Universities China (\#ZYGX2019J086), and Goldisc Research Program (\#190349).

\section{References}

Asche C, Said Q, Joish V, Hall CO, Brixner D (2008) Assessment of COPD-related outcomes via a national electronic medical record database. Int J Chron Obstruct Pulm Dis 3(2):323-326

Bai K-J, Chuang K-J, Chen J-K, Tsai C-Y, Yang Y-L, Chang C-C, Chen TT, Lee CN, Feng PH, Chen KY, Lee KY, Su CL, Ho SC, Wu SM, Chuang HC (2019) Alterations by air pollution in inflammation and metals in pleural effusion of pneumonia patients. Int $\mathrm{J}$ Environ Res Public Health 16(5):705

Chang C-C, Tsai S-S, Ho S-C, Yang C-Y (2005) Air pollution and hospital admissions for cardiovascular disease in Taipei, Taiwan. Environ Res 98(1):114-119

Chen Y, Yang Q, Krewski D, Shi Y, Burnett RT, McGrail K (2004) Influence of relatively low level of particulate air pollution on hospitalization for COPD in elderly people. Inhal Toxicol 16(1): $21-25$

Chen Z, Wang J-N, Ma G-X, Zhang Y-S (2013) China tackles the health effects of air pollution. Lancet (London, England) 382(9909): 1959

Çiftçi S, Düzgün Ș, Erkan BBB (2014) Risk analysis based on spatial analysis of chronic obstructive pulmonary disease (COPD) with respect to provinces in Turkey. J Comput Appl Math 259:413-424

Dominici F, McDermott A, Zeger SL, Samet JM (2002) On the use of generalized additive models in time-series studies of air pollution and health. Am J Epidemiol 156(3):193-203

Fang X, Wang X, Bai C (2011) COPD in China: the burden and importance of proper management. Chest. 139(4):920-929

Garshick E (2014) Effects of short-and long-term exposures to ambient air pollution on COPD. Eur Respir Soc 44:558

González P, Dominguez A, Moraga A (2019) The effect of outdoor PM 2.5 on labor absenteeism due to chronic obstructive pulmonary disease. Int J Environ Sci Technol 16(8):4775-4782

Guoliang LI. Clinical analysis of 42 cases of misdiagnosis in COPD with spontaneous pneumothorax. Heb Med. 2012.

Halonen JI, Lanki T, Yli-Tuomi T, Kulmala M, Tiittanen P, Pekkanen J (2008) Urban air pollution, and asthma and COPD hospital emergency room visits. Thorax. 63(7):635-641

Halpern MT, Stanford R, Borker R (2003) The burden of COPD in the USA: results from the Confronting COPD survey. Respir Med 97: S81-SS9 
Han L, Zhou W, Li W (2015) City as a major source area of fine particulate (PM2. 5) in China. Environ Pollut 206:183-187

Hoffmann C, Hanisch M, Heinsohn JB, Dostal V, Jehn M, Liebers U, Pankow W, Donaldson G, Witt C (2018) Increased vulnerability of COPD patient groups to urban climate in view of global warming. Int J Chron Obstr Pulm Dis 13:3493-3501

Hong-Wei H, Infection DO. Study on clinical diagnostic value of T cell detection of tuberculosis infection in patients with COPD and pulmonary tuberculosis. Chinese J Modern Drug Appl. 2019.

Jo YS, Lim MN, Han Y-J, Kim WJ (2018) Epidemiological study of PM2. 5 and risk of COPD-related hospital visits in association with particle constituents in Chuncheon, Korea. Int J Chron Obstr Pulm Dis 13:299

Kaji DA, Belli AJ, McCormack MC, Matsui EC, D'Ann LW, Paulin L et al (2014) Indoor pollutant exposure is associated with heightened respiratory symptoms in atopic compared to non-atopic individuals with COPD. BMC Pulm Med 14(1):147

Krahnke JS, Gangar JK, Shenoy KV, Albert RK, Voelker HT, Connett JE et al (2013) Chronic bronchitis symptoms in COPD patients vary by geographic climate region and season across the United States. C26 chronic obstructive pulmonary disease: implications of new gold stratification and phenotypes. Am Thorac Soc 201:A3944

Lee I-M, Tsai S-S, Chang C-C, Ho C-K, Yang C-Y (2007) Air pollution and hospital admissions for chronic obstructive pulmonary disease in a tropical city: Kaohsiung, Taiwan. Inhal Toxicol 19(5):393-398

Li L, Yang J, Song Y-F, Chen P-Y, Ou C-Q (2016) The burden of COPD mortality due to ambient air pollution in Guangzhou, China. Sci Rep 6:25900

Lin H, Qian ZM, Guo Y, Zheng Y, Ai S, Hang J et al (2018) The attributable risk of chronic obstructive pulmonary disease due to ambient fine particulate pollution among older adults. Environ Int 113:143-148

Lindberg A, Eriksson B, Larsson L-G, Rönmark E, Sandström T, Lundbäck B (2006) Seven-year cumulative incidence of COPD in an age-stratified general population sample. Chest. 129(4):879-885

Mannino DM, Buist AS (2007) Global burden of COPD: risk factors, prevalence, and future trends. Lancet 370(9589):765-773

Marsh S, Travers J, Weatherall M, Williams M, Aldington S, Shirtcliffe P et al (2008) Proportional classifications of COPD phenotypes. Thorax. 63(9):761-767

Mehrotra A, Oluwole AM, Gordon SB (2009) The burden of COPD in Africa: a literature review and prospective survey of the availability of spirometry for COPD diagnosis in Africa. Tropical Med Int Health 14(8):840-848

Meng X, Wang C, Cao D, Wong C-M, Kan H (2013) Short-term effect of ambient air pollution on COPD mortality in four Chinese cities. Atmos Environ 77:149-154

Ning G, Yim SHL, Wang S, Duan B, Nie C, Yang X, Wang J, Shang K (2019) Synergistic effects of synoptic weather patterns and topography on air quality: a case of the Sichuan Basin of China. Clim Dyn 53(11):6729-6744

Organization WH. Ambient air pollution: a global assessment of exposure and burden of disease. 2016.

Peacock JL, Anderson HR, Bremner SA, Marston L, Seemungal TA, Strachan DP, Wedzicha JA (2011) Outdoor air pollution and respiratory health in patients with COPD. Thorax. 66(7):591-596

Peng L, Xiao S, Gao W, Zhou Y, Zhou J, Yang D, Ye X (2020) Shortterm associations between size-fractionated particulate air pollution and COPD mortality in Shanghai, China. Environ Pollut 257: 113483

Qiao X, Jaffe D, Tang Y, Bresnahan M, Song J (2015) Evaluation of air quality in Chengdu, Sichuan Basin, China: are China's air quality standards sufficient yet? Environ Monit Assess 187(5):250
Qiu H, Yu ITS, Wang X, Tian L, Tse LA, Wong TW (2013) Season and humidity dependence of the effects of air pollution on COPD hospitalizations in Hong Kong. Atmos Environ 76:74-80

Qiu H, Tan K, Long F, Wang L, Yu H, Deng R, Long H, Zhang Y, Pan J (2018) The burden of COPD morbidity attributable to the interaction between ambient air pollution and temperature in Chengdu, China. Int J Environ Res Public Health 15(3):492

Qiu H, Zhu X, Wang L, Pan J, Pu X, Zeng X, Zhang L, Peng Z, Zhou L (2019) Attributable risk of hospital admissions for overall and specific mental disorders due to particulate matter pollution: a timeseries study in Chengdu, China. Environ Res 170:230-237

Ran J, Sun S, Yang A, Yang L, Han L, Mason TG, Chan KP, Li J, Tian L (2019) Effects of ambient benzene and toluene on emergency COPD hospitalizations: a time series study in Hong Kong. Sci Total Environ 657:28-35

Sadatsafavi M, Sin DD (2015) COPD: undefeated! Chest. 147(4):868869

Schikowski T, Adam M, Marcon A, Cai Y, Vierkötter A, Carsin AE et al (2014a) Association of ambient air pollution with the prevalence and incidence of COPD. Eur Respir J 44(3):614-626

Schikowski T, Mills IC, Anderson HR, Cohen A, Hansell A, Kauffmann F, Kramer U, Marcon A, Perez L, Sunyer J, Probst-Hensch N, Kunzli N (2014b) Ambient air pollution: a cause of COPD? Eur Respir J 43(1):250-263

Siddiqi TA, Chong-Xian Z (1984) Ambient air quality standards in China. Environ Manag 8(6):473-479

Sin DD, Anthonisen N, Soriano J, Agusti A (2006) Mortality in COPD: role of comorbidities. Eur Respir J 28(6):1245-1257

Stieb DM, Judek S, Burnett RT (2003) Meta-analysis of time-series studies of air pollution and mortality: update in relation to the use of generalized additive models. J Air Waste Manage Assoc 53(3):258 261

Sullivan SD, Ramsey SD, Lee TA (2000) The economic burden of COPD. Chest. 117(2):5S-9S

Sun XW, Chen PL, Ren L, Lin YN, Zhou JP, Ni L et al (2018) The cumulative effect of air pollutants on the acute exacerbation of COPD in Shanghai, China. Sci Total Environ 622:875-881

Thom TJ (1989) International comparisons in COPD mortality. Am Rev Respir Dis 140(3 Pt 2):S27-S34

Tian Y, Liu H, Wu Y, Si Y, Song J, Cao Y, et al. Association between ambient fine particulate pollution and hospital admissions for cause specific cardiovascular disease: time series study in 184 major Chinese cities. bmj. 2019;367.

Wang W, Ying Y, Wu Q, Zhang H, Ma D, Xiao W (2015) A GIS-based spatial correlation analysis for ambient air pollution and AECOPD hospitalizations in Jinan, China. Respir Med 109(3):372-378

Weiß G, Lamprecht B, Kaiser B, Studnicka M (2010) Health care costs in COPD: misuse of resources as a consequence of over-diagnosed disease. Biol Trace Elem Res 136(2):127-139

Yin P, Wang H, Vos T, Li Y, Liu S, Liu Y, Liu J, Wang L, Naghavi M, Murray CJL, Zhou M (2016) A subnational analysis of mortality and prevalence of COPD in China from 1990 to 2013: findings from the global burden of disease study 2013. Chest. 150(6): $1269-1280$

Zeger SL, Thomas D, Dominici F, Samet JM, Schwartz J, Dockery D, Cohen A (2000) Exposure measurement error in time-series studies of air pollution: concepts and consequences. Environ Health Perspect 108(5):419-426

Zhang Y, Wang Z, Xu J, Liu Y, Zhou B, Zhang N, et al., editors. Association between consecutive ambient air pollution and chronic obstructive pulmonary disease hospitalization: time series study during 2015-2017 in Chengdu China. 2020 42nd Annual International Conference of the IEEE Engineering in Medicine \& Biology Society (EMBC); 2020: IEEE. 
Zhu X, Qiu H, Wang L, Duan Z, Yu H, Deng R, Zhang Y, Zhou L (2019) Risks of hospital admissions from a spectrum of causes associated with particulate matter pollution. Sci Total Environ 656:90-100
Publisher's note Springer Nature remains neutral with regard to jurisdictional claims in published maps and institutional affiliations.

\section{Affiliations}

Yi Zhang ${ }^{1,2}$ (D) $\cdot$ Ziyue Wang ${ }^{1,2} \cdot$ Yu Cao $^{1,2} \cdot$ Lifu Zhang $^{1,2} \cdot$ Guan Wang $^{1,2} \cdot$ Fangjie Dong $^{3} \cdot$ Ren Deng $^{4} \cdot$ Baogen Guo $^{5}$. Li Zeng $^{6} \cdot$ Peng Wang ${ }^{7} \cdot$ Ruimei Dai $^{8} \cdot$ Yu Ran ${ }^{1,2} \cdot$ Wenyi Lyu ${ }^{1,2} \cdot$ Peiwen Miao ${ }^{9} \cdot$ Steven Su ${ }^{10}$

1 The School of Aeronautics and Astronautics, University of Electronic Science and Technology of China, Chengdu 611731, China

2 Aircraft Swarm Intelligent Sensing Cooperative Control Key Laboratory of Sichuan Province, University of Electronic Science and Technology of China, Chengdu 611731, China

3 The Centre for Health Statistics and Information National Health Commission of the P.R. of China, Beijing 100000, China

4 Health Information Center of Sichuan Province, Chengdu 611731, China
5 TCM Hospital of Shuangliu District, Chengdu 610200, China

6 Longchang People's Hospital, Neijiang 642150, China

7 The People's Hospital of Weiyuan, Weiyuan 642450, China

8 Sichuan Post and Telecommunication College, Chengdu 610067, China

9 Sichuan Agricultural University, Chengdu 625014, China

10 The Biomedical Engineering School, University of Technology Sydney, Ultimo, NSW 2007, Australia 